Purdue University Purdue e-Pubs

2010

\title{
Heat Transfer in Trapezoidal Microchannels of Various Aspect Ratios
}

John P. McHale

Purdue University - Main Campus

S V. Garimella

Purdue University, sureshg@purdue.edu

Follow this and additional works at: http://docs.lib.purdue.edu/coolingpubs

McHale, John P. and Garimella, S V., "Heat Transfer in Trapezoidal Microchannels of Various Aspect Ratios" (2010). CTRC Research Publications. Paper 121.

http://dx.doi.org/10.1016/j.ijheatmasstransfer.2009.09.020

This document has been made available through Purdue e-Pubs, a service of the Purdue University Libraries. Please contact epubs@purdue.edu for additional information. 


\title{
Heat Transfer in Trapezoidal Microchannels of Various Aspect Ratios ${ }^{1}$
}

\author{
John P. McHale and Suresh V. Garimella ${ }^{2}$ \\ Cooling Technologies Research Center \\ School of Mechanical Engineering and Birck Nanotechnology Center \\ Purdue University, West Lafayette, Indiana 47907-2088 USA
}

\begin{abstract}
Heat transfer in the thermal entrance region of trapezoidal microchannels is investigated for hydrodynamically fully developed, single-phase, laminar flow with no-slip conditions. Three-dimensional numerical simulations were performed using a finite-volume approach for trapezoidal channels with a wide range of aspect ratios. The sidewall angles of $54.7^{\circ}$ and $45^{\circ}$ are chosen to correspond to etch-resistant planes in the crystal structure of silicon. Local and average Nusselt numbers are reported as a function of dimensionless length and aspect ratio. The effect of Prandtl number upon the thermal entrance condition is explored. The fully developed friction factors are computed and correlated as a function of channel aspect ratio. Correlations are also developed for the local and average Nusselt numbers in the thermal entrance region as a function of a dimensionless axial length variable.
\end{abstract}

Keywords: Microchannel, thermally developing, liquid cooling, heat sink, trapezoid

\footnotetext{
${ }^{1}$ Submitted for publication in International Journal of Heat and Mass Transfer, February 2009, and in revised form, August 2009

${ }^{2}$ Author to whom correspondence should be addressed: 765-494-5621, sureshg@purdue.edu
} 


\section{NOMENCLATURE}

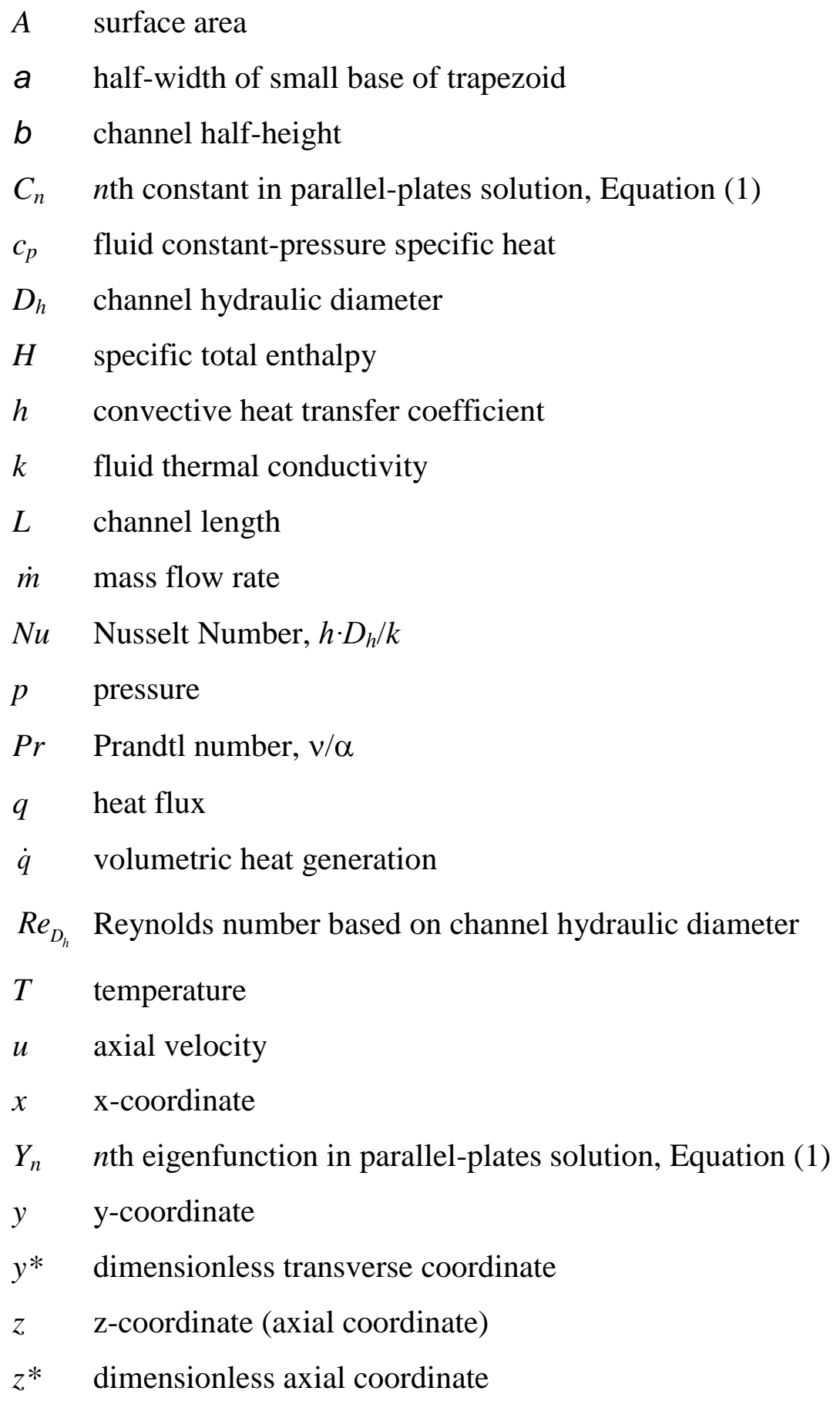

\section{Greek}

$\alpha \quad$ channel aspect ratio, $2 a / 2 b$

$\gamma_{n} \quad n$th eigenvalue in parallel-plates solution, Equation (1) 
$\zeta \quad$ dimensionless axial coordinate normalized by thermal development length, $z^{*} / L^{*}{ }_{t h}$

$\mu \quad$ fluid dynamic viscosity

$v \quad$ fluid kinematic viscosity

$\rho \quad$ fluid density

$\phi \quad$ channel sidewall angle

\begin{tabular}{|c|c|}
\hline \multicolumn{2}{|c|}{ Subscripts } \\
\hline$a v g$ & average \\
\hline$f$ & fluid \\
\hline$f d$ & fully developed \\
\hline$m$ & mean \\
\hline$n$ & summation index \\
\hline$w$ & wall \\
\hline$z$ & local \\
\hline
\end{tabular}

\section{INTRODUCTION}

Common fabrication techniques enable the production of many different microchannel cross-sectional shapes, including rectangular, circular, triangular, and trapezoidal. The use of an anisotropic etchant such as potassium hydroxide $(\mathrm{KOH})$ or tetramethylammonium hydroxide (TMAH) produces a geometry in a silicon substrate which is either trapezoidal or triangular, depending upon the depth to which etching is allowed to proceed. These etchants have a high (100 250:1) selectivity to the (100) and (110) crystal planes relative to the (111) crystal plane, producing a channel sidewall angle of approximately $54.7^{\circ}$ or $45^{\circ}$, depending upon the orientation of the patterned geometry [1,2]. Anisotropic etching processes are relatively fast and inexpensive; thus, production of microchannels may be readily integrated into the chip fabrication process stream if desired. Thus trapezoidal microchannels hold promise for integrated heat sinking and lab-on-a-chip applications, the design of which is dependent upon the fluid flow and heat transfer behaviors of these channels. The unique conditions of liquid flow and heat transfer in uniformly heated trapezoidal microchannels has not been considered in detail in the literature. The present work reports thermally developing flow solutions over the entire 
range of possible aspect ratios and provides correlations for predicting friction factors and local and average Nusselt numbers in ducts under the given conditions.

Much effort has been directed in recent years to characterize the heat transfer behavior of fluid flow in ducts of various shapes and sizes. Studies that are most relevant to the current work are compared in Table 1. Friction factor and Nusselt number values for fully developed, thermally developing, hydrodynamically developing, and simultaneously developing conditions from the literature have been catalogued by Shah and London [3] and Kakac, et al. [4]. These results have been applied to predict the behavior of microchannels beginning with Tuckerman and Pease [5]. It has been shown by Judy, et al. [6], Liu and Garimella [7], and Lee, et al. [8] that microchannel flow and heat transfer exhibit continuum behavior in single-phase flows for channel dimensions of interest in high-flux cooling applications. Therefore, results from macroscale channels can be directly applied to such microchannels. However, flow in microchannels may not generally be assumed to be fully developed. Shah [9] summarized his studies of compact heat exchangers and noted the effects of flow development on the thermal performance. Phillips [10] extended these conclusions to microchannel heat sinks and recommended that flow be considered thermally developing but hydrodynamically fully developed. Lee, et al. [8] showed by comparing experimental and numerical data from rectangular microchannels that the assumption of thermally developing flow (TDF) predicts average Nusselt numbers within $5 \%$ of the experimental values over the entire range of laminar Reynolds numbers. A departure was observed beginning at Reynolds numbers between 1500 and 2000, and was attributed to the beginning of transition to turbulent flow. Numerical results were also compared to show that the $\mathrm{H1}$ boundary condition described in [3] effectively represents the 3-D conjugate heat transfer occurring in a microchannel heat sink.

Limited heat transfer and friction factor results are available for ducts with a sidewall angle of $54.7^{\circ}$. Harley, et al. [11] experimentally investigated the frictional pressure drop for flow through channels etched in $\langle 100\rangle$ - and $\langle 110\rangle$-oriented silicon for a variety of fluids. For small trapezoidal channels, the experimentally observed friction factors were significantly higher than those predicted for fully developed flow. Flockhart and Dhariwal [12] experimentally and numerically determined fully developed friction factors in trapezoidal channels with $54.7^{\circ}$ sidewall angles and found good agreement between the two; for channels of shorter length, however, there was less agreement, which could be attributed to flow development effects not 
having been considered. Farhanieh and Sunden [13] examined heat transfer in the hydrodynamic entrance region of isosceles trapezoidal ducts using a finite volume method, but their results were limited to developing-flow friction factors and fully developed Nusselt numbers for sidewall angles of $30^{\circ}, 45^{\circ}, 60^{\circ}$, and $90^{\circ}$. Using a successive grid length ratio in the streamwise direction and uniform spacing in the other two directions, they showed that satisfactory agreement could be achieved with theoretical results from Shah and London [3]. Rujano and Rahman [14] obtained results from a numerical analysis for a sidewall angle of $54.7^{\circ}$; their results were compared to experiments with relatively good agreement, but the numerical values for Nusselt number were consistently lower than the experimental ones. The results did not accurately reproduce the expected local Nusselt number at $z^{*}=0$ and were not generalized for a range of parameters. Heat transfer and pressure drop in trapezoidal microchannels with a $54.7^{\circ}$ sidewall angle and with three heated walls were experimentally investigated by Qu, et al. $[15,16]$, who obtained good agreement with theory when an adjusted coolant viscosity was included to account for surface roughness of the channels. Rahman and Shevade [17] experimentally and numerically studied flow in trapezoidal microchannels with heating on all four walls, and concluded that the effects of thermal boundary layer development were significant. Wu and Cheng experimentally investigated both friction factors [18] and heat transfer [19] in trapezoidal microchannels, while considering the effects of other parameters such as surface conditions. They found that channel geometry had a much more significant effect on the Nusselt number than did roughness or hydrophilicity of the wall surfaces. Correlations fit to their data did not explicitly include the effects of dimensionless length.

Other researchers have used numerical methods to study mainly fully developed flow in equilateral and isosceles triangular channels [20,21]. Sadasivam, et al. [22] provided correlations for Nusselt numbers and friction factors under fully developed conditions in trapezoidal and hexagonal ducts with sidewalls at $30^{\circ}, 45^{\circ}, 60^{\circ}$, and $75^{\circ}$ based on finitedifference solutions. Bahrami, et al. used the similarity between the governing equations of beam torsion and fluid flow in ducts to develop an approximate method for predicting pressure drop in ducts of arbitrary cross section including a trapezoidal shape [23] and randomly rough microtubes [24]. They then extended the work to evaluate the heat transfer in rough microchannels [25] and found little enhancement due to reasonable values of surface roughness. Steinke and Kandlikar [26] compared many of the results in the literature for single-phase 
friction factors in different microchannel shapes. Rokni and Sunden [27] investigated fully developed friction factors and Nusselt numbers under turbulent conditions in trapezoidal ducts with a small set of sidewall angles and aspect ratios.

Thermally developing flow in microchannels of different shapes has been investigated by several researchers. Wei and Joshi [28] combined two of Shah's correlations [29,30] in order to predict the thermally developing Nusselt number in rectangular channels. More recently, Lee and Garimella [31] conducted a detailed study of heat transfer in thermally developing flow through rectangular microchannels of various aspect ratios, and developed generalized correlations for local and average Nusselt numbers. Talukdar and Shah [32] studied mixed convection in triangular ducts with simultaneously developing conditions and found that the local Nusselt number fluctuated along the channel length due to buoyancy-driven circulation. Renksizbulut and Niazmand [33] numerically studied the entrance region of trapezoidal channels with sidewalls at $30^{\circ}, 45^{\circ}, 60^{\circ}$, and $90^{\circ}$, and aspect ratios of $0.5,1.0$, and 2.0 , recommending correlations for $f R e, N u_{f d}$, and entrance length. Niazmand, et al. [34] extended the analysis to include slip flow over a slightly wider range of channel aspect ratios, modifying the previous correlation to include the effects of velocity slip at the wall. The velocity and temperature fields were considered to be simultaneously developing, with a fluid having $\operatorname{Pr}=1$, and the thermal boundary condition was the uniform temperature, or $\odot$, condition. Wang, et al. [35] compared experimental and numerical results for simultaneously developing water flow in a trapezoidal microchannel with $54.7^{\circ}$ sidewalls and a single uniformly heated wall. The predictions were found to agree well with the experiments confirming the applicability of the continuum assumption for the Navier-Stokes equations; a thermal development length was also identified.

The present study follows on the recommendations of Lee, et al. [8] for liquid flow in microchannels and applies the $\mathrm{H1}$ boundary the trapezoidal channel with sidewalls at $54.7^{\circ}$ or $45^{\circ}$. The purpose of this study is to explore the effect of aspect ratio and axial length upon the local and average heat transfer coefficients in the trapezoidal duct, and to provide generalized correlations for the corresponding Nusselt numbers and friction factors. The results of this study are helpful for the design and optimization of trapezoidal microchannel heat sinks. 


\section{MATHEMATICAL FORMULATION}

Exact solutions are available for thermally developing flow in parallel plates and circular pipes [29,36-43]. The solution to the parallel-plates problem provides a foundation for understanding the general characteristics of thermally developing flow. Sparrow, et al. [43] derived the solution for a variety of boundary conditions, including prescribed temperature, prescribed heat flux, and energy generation within the fluid. Shah and London [3] simplified the results of [43] for constant fluid properties, for no internal energy generation, and with axial conduction neglected, to the following form:

$$
\frac{1}{N u_{z}}=\frac{17}{140}+\frac{1}{4} \sum_{n=1}^{\infty} C_{n} \cdot Y_{n}(1) \cdot e^{-(32 / 3) \gamma_{n}^{2} z^{*}}
$$

where $\gamma_{n}, Y_{n}$, and $C_{n}$ are eigenvalues, eigenfunctions, and constants, respectively, related to the Sturm-Liouville system [43] with Neumann boundary conditions

$$
\frac{d^{2} Y_{n}}{\left(d y^{*}\right)^{2}}+\gamma_{n}^{2}\left(1-\left(y^{*}\right)^{2}\right) Y_{n}=0,\left.\quad \frac{d Y_{n}}{d y^{*}}\right|_{y^{*}=0,1}=0
$$

in which $y^{*}$ is the dimensionless transverse coordinate. The series in Equation (1) is evaluated numerically using the first 500 terms in the series solution and plotted against nondimensional length in Figure 1. In the figure, the three curves shown are the local Nusselt number $N u_{z}$, the mean Nusselt number $N u_{m}$, obtained by integration from the channel entrance to the point of interest, and an average Nusselt number $N u_{a v g}$, to be discussed in the next section with Equation (8). Superposed are data tabulated by Shah [29], obtained using 121 terms of Equation (1). The curves in Figure 1 have three distinct portions: a thermal development region, in which the Nusselt number tends toward infinity on one end of this portion as length goes to zero and approaches the fully developed value on the other end at a constant log-log slope; a transition into the fully developed region; and the fully developed region in which Nusselt number is constant. While the transition region appears to be very small, it will be shown that this is the region of the curve of primary interest at the typical length scales for microchannels.

The axial coordinate $z$ can be nondimensionalized as [3]:

$$
z^{*}=\frac{z}{D_{h} \cdot \operatorname{Re} \cdot \operatorname{Pr}}
$$


Full thermal development is usually reached, depending upon channel shape and other considerations, at a $z^{*}$ value on the order of $10^{-2}$ to $10^{-1}$. In microchannels, even a liquid with a moderately low Prandtl number flowing at sufficiently high Reynolds numbers results in thermally developing flow over a significant portion of the channel length. For example, for water $(\operatorname{Pr} \approx 6)$ flowing through a $1-\mathrm{cm}$ microchannel with $D_{h}=100 \mu \mathrm{m}$ and $\operatorname{Re}=200$, the entire channel length is in the thermally developing and transition regions.

In the present study, local and average Nusselt numbers are sought for a generalized trapezoidal microchannel with geometric parameters as shown in Figure 2 (a). Channel aspect ratios varying from 0 (triangular) to 100 are considered by holding the height $2 b$ and length $L$ constant at $250 \mu \mathrm{m}$ and $5 \mathrm{~m}$, respectively, and the dimensional scaling parameter $D_{h} \operatorname{Re} P r$ at 21 $\mathrm{m}$; the base half-width $a$ is varied from 0 to $12.5 \mathrm{~mm}$, as listed in Table 2 . Sidewall angle $\phi$ is held constant at $54.7^{\circ}$ or $45^{\circ}$. At values of $\alpha$ greater than 100, the 2-D parallel-plates solution to Equation (1) is assumed for both sidewall angles.

The governing equations to be solved are the full 3-dimensional Navier-Stokes momentum, continuity, and energy equations [44,45]. The problem is not amenable to exact analytical solution, and therefore the problem is solved numerically. The boundary conditions for the flow are the no-slip condition at each of the walls, a fully developed velocity profile at the inlet (a constraint that is relaxed in a later section), and uniform zero pressure at the outlet. The boundary conditions for the energy equation are the $\mathrm{H1}$ thermal condition described in [3] and a uniform inlet fluid temperature of $25^{\circ} \mathrm{C}$. $\mathrm{H1}$ is defined as uniform temperature of the duct wall in the peripheral direction and uniform heat flux in the axial direction. The following conditions are also applied: steady state; incompressible, laminar flow; no viscous dissipation of energy nor gravitational (buoyancy) effects; negligible axial conduction in the fluid and in the wall; and constant fluid properties.

Under these conditions, the development of the thermal boundary layer should result in Nusselt numbers similar to those in Figure 1. The solution must satisfy the analytical limits of infinite $N u_{z}$ at $z^{*}=0$, a constant log-log slope over most of the thermal development region, and a smooth, rapid transition to the constant, fully developed value. It will be shown that the present results agree well with analytical solutions with respect to these three characteristics. 


\section{Solution Method}

The computations were conducted using the commercial computational fluid dynamics software, FLUENT [44]. The SIMPLE algorithm was chosen to solve for the flow field. Only one half of the domain was included in the computations from symmetry considerations. The fully developed velocity profile was first computed using an extended domain upstream, and the outlet velocity profile from this upstream domain was applied as the inlet velocity profile to the primary domain. The upstream domain was sufficiently long to produce negligible $\left(\sim 10^{-6} \cdot u_{z}\right) x$ and $y$ - velocity components, indicating fully developed conditions. The momentum and energy equations were then solved for thermally developing flow in the primary domain. In order to accurately capture the extremely high temperature gradients near the wall in the entrance region, while still maintaining a manageable number of cells, it was necessary to tailor the mesh as shown in Figure 2 (b). The mesh geometry includes very close packing of cells near the geometric boundaries at the entrance, both in the axial and transverse directions, while towards the channel exit, a uniform mesh was sufficient. In order to achieve satisfactory results, the ratio of successive cell dimensions was held to be generally less than 1.025 in the axial direction and less than 1.25 in the transverse directions. The larger cells towards the center of the channel cross section are permissible because the temperature gradients in this region are negligible and flow velocities are known from the imposed flow profile. In order to directly compare the results of the 3-D numerical analysis with the 2-D analytical solution, Equation (1), the assumption of neglible axial conduction within the fluid must be valid. In order to keep the axial component of heat conduction within the fluid negligibly small, the cell Peclet number was made large (> 400 for all cells) by increasing the channel length and the fluid Prandtl number. The $\mathrm{H1}$ boundary condition in the solid wall was implemented by applying a uniform heat flux on the outer wall of the solid zone and setting anisotropic thermal conductivities of the solid material to be $1 \times 10^{6}$ $\mathrm{W} / \mathrm{m}-\mathrm{K}$ in the $x$ - and $y$-directions and $1 \times 10^{-30} \mathrm{~W} / \mathrm{m}-\mathrm{K}$ in the $z$-direction.

Following the work of Lee and Garimella [31], the local Nusselt number may be calculated from the numerical results using:

$$
N u_{z}=\left(\frac{D_{h}}{k_{f}}\right) h(z)
$$


where

$$
h(z)=\frac{\sum_{x, y} q^{\prime \prime}(x, y, z) d A(x, y, z)}{\sum_{x, y}\left[T_{w}(x, y, z)-T_{m}(z)\right] d A(x, y, z)}
$$

and the local bulk mean fluid temperature can be determined from an energy balance on the fluid:

$$
T_{m}(z)=T_{i n}+\frac{1}{\dot{m} c_{p}} q^{\prime \prime} \sum_{x, y, z} d A(x, y, z)
$$

The average heat transfer coefficient is calculated as in Lee and Garimella [31]:

$$
h_{\text {avg }}(z)=\frac{\sum_{x, y, z} q^{\prime \prime}(x, y, z) d A(x, y, z)}{\sum_{x, y, z}\left[T_{w}(x, y, z)-T_{m}(z)\right] d A(x, y, z)}
$$

For the $\mathrm{H} 1$ boundary condition, $T_{w}$ becomes a function only of $z$. Additionally, for a uniform channel cross section, Equation (7) may be simplified to:

$$
N u_{\text {avg }}(z)=\left(\frac{D_{h}}{k_{f}}\right) h_{\text {avg }}(z)=\left[\frac{1}{z^{*}} \sum_{z} \frac{1}{N u_{z}} d z^{*}\right]^{-1}
$$

It is noted that the definition of the average Nusselt number in this work typically differs by as much as $12.5 \%$ from the mean Nusselt number as defined by Shah and London [3] and others, as may be seen in the parallel-plates solution of Figure 1. $N u_{m}$ is based upon an integration of $N u_{z}$ rather than its inverse. The definition given by Equation (7) effectively integrates the temperature difference and is therefore more readily applicable to bulk thermal resistance calculations. To quantify the performance of an entire microchannel heat sink, the average convection resistance should represent the area-averaged difference between wall and bulk mean fluid temperatures per unit heat flow. Under the definition in [3], however, the inverse of that temperature difference is area-averaged via the Nusselt number; the average temperature difference between the wall and the fluid implied by that approach is the log-mean temperature difference [45].

\section{Grid Independence}

Results were obtained with three different grids to establish grid-independence: $15 \times 20 \times$ $365,30 \times 40 \times 365$, and $40 \times 60 \times 365$ for channel aspect ratios of 2 and 10, and are shown in 
Figure 3 (a). For $\alpha=2$ the difference in local Nusselt number between the finest mesh and the coarsest mesh at the first inlet cell was $48 \%$; the typical difference over the domain length was between $1 \%$ and $5 \%$. The maximum difference between the medium mesh and the finest mesh was less than $0.6 \%$, and this difference was less than $0.1 \%$ over the majority of the domain length. Similar results were observed for $\alpha=10$.

Results from three different discretization schemes - first-order upwind, second-order upwind, and third-order QUICK schemes [44] - were also compared for the $15 \times 20 \times 365$ grid, as shown in Figure 3 (b). The first-order and the second-order curves differed by as much as 5\% in the transition region and $1.5 \%$ in the fully developed region. Improving the discretization to a third-order scheme resulted in no significant change over most of the channel and less than $1 \%$ in a small part of the transition region. All quantities of interest were therefore solved on a $30 \times 40$ $\times 365$ grid using a second-order approximation.

The numerical analysis was also verified to be independent of the geometric scale by comparing results for a channel aspect ratio of $\alpha=2$ at hydraulic diameters differing by a factor of 100, but with identical dimensionless parameters. The difference in the calculated Nusselt numbers was less than $0.5 \%$.

\section{Validation of Numerical Approach}

Predictions from the numerical analysis are compared to analytical solutions for fully developed Nusselt number $N u_{f d}$ and friction constant $f R e$. The method used to calculate these values analytically for an arbitrary duct shape is described in Shah [30]; most of the original data for various duct shapes reported in [3] were generated by this method. The z-momentum equation is converted to the Laplace equation through a coordinate transformation, for which an infinite series solution is available. For a finite number of terms, the coefficients in the series are determined so that the error of the solution at an arbitrary number of points on the boundary is minimized. The temperature field is then solved by a similar approach. For aspect ratios greater than 8 , the number of terms needed to accurately describe the velocity and temperature profile makes matrix inversion for a least-squares solution difficult. The method of Householder reflections was used to compute all the inversions robustly. Predictions from the present study are compared in Table 3 to the analytical results obtained by this method and, where available, to Shah's tabulated data from [30]. For $\phi=45^{\circ}$ the predictions agree with the analytical results at 
all aspect ratios to within $1.03 \%$ for $N u_{f d}$ and to within $0.51 \%$ for $f R e$. The analytical results agree with those from [30] to within $0.46 \%$ for $N u_{f d}$ and to within $0.19 \%$ for $f R e$. For $\phi=54.7^{\circ}$, a few points exhibit discrepancies of up to $4 \%$ for $f R e$.

\section{RESULTS AND DISCUSSION}

Fully developed friction constants $f R e$ were calculated for each channel aspect ratio using the pressure drop across the entire channel length and are shown in Figure 4. For both channel sidewall angles, $\phi=54.7^{\circ}$ and $45^{\circ}$, the aspect ratio is seen to have a significant effect on $f R e$. For channels that are more triangular, i.e., as $\alpha \rightarrow 0, f R e$ is small $(13 \sim 14)$, but for $1<\alpha<100$, the value of $f R e$ increases approximately as $\log (\alpha)$. The upper limit of $f R e=24$ (parallel plates) is approached slowly as $\alpha \rightarrow \infty$. These data agree well with [30] and with analytical solutions, as compared in Table 3.

Local and average Nusselt numbers were calculated as a function of dimensionless axial length for each aspect ratio, with the resulting families of curves for $\phi=54.7^{\circ}$ plotted in Figure 5 (a) and (b), respectively. For each curve in Figure 5 (a), the local Nusselt number in the entrance region follows an exponential relationship with $z^{*}$. Upon nearing the thermal development length $L_{t h}^{*}$, a smooth transition to the fully developed value for the Nusselt number is apparent, after which $N u_{z}$ remains constant. The average Nusselt number $N u_{a v g}$, plotted in Figure 5 (b), follows a similar trend, but lags the local Nusselt number as expected; the fully developed value is only approached asymptotically due to the prolonged influence of the high $N u_{z}$ values in the entrance region. These characteristics are consistent with the analytical solution for parallel plates described above.

The curves for both local and average Nusselt number exhibit a clear correlation with channel aspect ratio. The fully developed Nusselt number $N u_{f d}$ and the thermal development length $L_{t h}^{*}$ are the key parameters that change with channel aspect ratio $a$, as shown in Figure 6 for the $54.7^{\circ}$ and the $45^{\circ}$ sidewall angles. For both sidewall angles, $L_{t h}^{*}$ is shown to decrease from approximately 0.07 to 0.012 as channel aspect ratio is increased from 0 to $\infty$. The fully developed Nusselt number increases from approximately 3 for triangular channels, up to 8 for channels with large aspect ratios. Comparisons are given in Table 3 between numerically determined values of $N u_{f d}$ from the present study, values of $N u_{f d}$ tabulated in [30] for $45^{\circ}$ 
sidewalls, and analytical solutions from the present work following the method of Shah [30].

Correlation equations for $f R e, N u_{f d}$, and $L_{t h}^{*}$ were obtained by means of a nonlinear leastsquares regression of the results calculated from the numerical model, applied to sigmoid equation forms bearing either double exponential or arctangent functions, and are discussed below.

\section{Friction Constant Correlations}

The friction constants $f R e$ for channels with $\phi=54.7^{\circ}$ and $45^{\circ}$ are correlated according to Equations (9) and (12), respectively, which are listed in Table 4. The correlations are applicable for a wide range of channel aspect ratios spanning from $\alpha=0$ to approximately 1100, beyond which the duct may be treated as a parallel-plates channel with $f R e=24$. The mean absolute errors of Equations (9) and (12) with respect to the numerical data are $0.25 \%$ for $45^{\circ}$ sidewalls and $1.20 \%$ for $54.7^{\circ}$ sidewalls. Equations (9) and (12) are shown in Figure 4 along with the numerically predicted values from this work. Also included are the experimental data of $\mathrm{Wu}$ and Cheng [18], and the correlations from [18] and from Sadasivam, et al. [22] for $\phi=54.7^{\circ}$ and $45^{\circ}$, respectively. Good agreement is noted between the present correlations and prior work. The correlation of $\mathrm{Wu}$ and Cheng [18] for $\phi=54.7^{\circ}$ fits their experimental data well, but the limits at $\alpha=0$ and $\infty$ deviate from the theoretical values by up to $8 \%$. The present correlation for $\phi=45^{\circ}$ requires fewer constants than that of [22] to achieve excellent accuracy.

\section{Nusselt Number Correlations}

Fully developed Nusselt numbers $N u_{f d}$ for channels with $\phi=54.7^{\circ}$ and $45^{\circ}$ are correlated in terms of $\alpha$ according to Equations (10) and (13), given in Table 4. Corresponding correlations

for the thermal entrance lengths $L_{t h}^{*}$ are given in Equations (11) and (14). Each of these equations is piecewise continuous, having three sections: constants at the very small and very large aspect ratios, and an intervening sigmoid section fit to aspect ratios from 0.1 to approximately 200 . The mean absolute errors of the correlations with respect to the numerical computations are less than $0.5 \%$ for $N u_{f d}$ and less than $1.5 \%$ for $L_{t h}^{*}$. Equations (10) and (11) are plotted in Figure 6 (a) along with the numerical predictions for channels with $\phi=54.7^{\circ}$, while a similar plot with Equations (13) and (14) is presented in Figure 6 (b) for channels with $\phi=45^{\circ}$. 
A new dimensionless coordinate $\zeta$, defined as

$$
\zeta \equiv \frac{z^{*}}{L_{t h}^{*}}=\frac{z}{L_{t h}},
$$

may be used as a quantitative measure of the extent to which a flow has developed thermally. A value of $\zeta=1$ indicates nearly full thermal development, i.e., $N u_{z} / N u_{f d}=1.05$, which is an arbitrary value recommended in the literature [3]. The magnitude of enhancement of local and average Nusselt numbers for a given value of $\zeta$ is shown from the present results to be independent of channel aspect ratio, to a good approximation. The local and average Nusselt numbers for a channel of any aspect ratio may therefore be reduced to functions only of $\zeta$ and $N u_{f d}$. The correlations provided by Shah [29] for local and average Nusselt number can be generalized in this manner, with minor adjustments to improve the accuracy, according to Equations (15) and (16) in Table 4. Although from the numerical data, $N u_{z}$ is found to vary as $\zeta$ to the power of an exponent that ranges between -0.31 and -0.35 , a single exponent of $-1 / 3$ is used in the first segment of Equations (15) and (16) to represent this dependence as dictated by theoretical analysis for two-dimensional cases. The second segment of Equation (16) includes an exponent of -0.29 to improve continuity between the first and third segments of Equation (16).

For trapezoidal microchannels with $54.7^{\circ}$ sidewalls, Equations (10) and (11) are applied along with Equations (15) and (16) to predict local and average Nusselt numbers as functions of channel aspect ratio and normalized axial coordinate $\zeta$. These results are compared with $N u_{z}$ and $N u_{\text {avg }}$ from the numerical analysis for representative aspect ratios of 1, 5, and 10 in Figure 7. The correlations typically deviate from the numerical results by less than $2 \%$ to $3 \%$, although the discrepancies are higher for small $(<1)$ aspect ratios at very small $\zeta$ values. Equation $(15)$ predicts $N u_{z}$ to within $\pm 1.5 \%$ of the exact values known for parallel plates.

\section{Comparison to Simultaneously Developing Flow}

Thermally developing flow (TDF) is the condition assumed for predicting microchannel heat transfer in all the results presented thus far, according to the recommendations of Lee, et al. [8] and Phillips [10]. In practice, however, some extent of simultaneously developing flow (SDF) is expected to be present in microchannel heat sinks. In SDF, the additional effect of hydrodynamic boundary layer growth contributes to a higher Nusselt number in the entrance 
region. The TDF assumption is essentially a high-Prandtl $(\operatorname{Pr}>>1)$ assumption. For a Prandtl number near unity, such as for most gases, or much less than unity, such as for liquid metals, the importance of hydrodynamic boundary layer growth in the entrance region should be considered as well.

Simultaneously developing flow was simulated in a microchannel with $\alpha=2$ and $\phi=$ $54.7^{\circ}$ by applying a uniform (slug-flow) velocity profile at the inlet and setting fluid properties to match the Prandtl number of four different fluids: ethylene glycol $(\operatorname{Pr}=150)$, water $(\operatorname{Pr}=7)$, air $(\operatorname{Pr}=0.74)$, and mercury $(\operatorname{Pr}=0.025)$. Local Nusselt numbers for these fluids computed using SDF assumptions are compared to the TDF case in Figure 8. The comparison indicates that hydrodynamic boundary layer development provides an additional enhancement of local Nusselt number. For design problems in which the temperature of the wall rather than that of the fluid is of primary interest, the TDF assumption provides a conservative (lower) estimate for local and average Nusselt numbers in the entrance region. Since the TDF model has resulted in good agreement between experiment and simulation in microchannel heat sinks ([8] and [10]), the TDF assumption is still suitable in general for liquid flow in microchannels, for which Equations (15) and (16) are recommended.

\section{CONCLUSIONS}

Numerical results are obtained and summarized for thermally developing flow (TDF) with the $\mathrm{H1}$ boundary condition in trapezoidal microchannels with sidewall angles $54.7^{\circ}$ and $45^{\circ}$ over a wide range of aspect ratios. Using carefully constructed grids, local and average heat transfer coefficients in the entrance region of these 3-dimensional channels are found to be proportional to $\left(z^{*}\right)^{-1 / 3}$ in the entrance region, which is identical to the proportionality predicted by the 2-D Graetz-Lévêque solutions. Changing the aspect ratio $\alpha$ or sidewall angle $\phi$ of the channel affects both the fully developed value of Nusselt number $N u_{f d}$ and the thermal entrance length $L_{t h}^{*}$. Normalization of the axial length variable $z^{*}$ by $L_{t h}^{*}$ and the local Nusselt number $N u_{z}$ by $N u_{f d}$ allows the modification of Shah's [29] thermally developing flow correlations for application to the trapezoidal channels considered here; these new correlations for local and average Nusselt numbers are given in Equations (15) and (16). 


\section{Acknowledgment}

The authors thank the members of the Cooling Technologies Research Center, a National Science Foundation Industry/University Cooperative Research Center at Purdue University, for their financial support. Technical discussions with Dr. Jayathi Murthy and Dr. Poh-Seng Lee are also gratefully acknowledged.

\section{REFERENCES}

[1] E. Vazsonyi, Z. Vertesy, A. Toth, J. Szlufcik, Anisotropic etching of silicon in a twocomponent alkaline solution, J. Micromech. Microeng. 13 (2003) 165-169.

[2] Virginia Semiconductor Inc., Wet chemical etching and cleaning of silicon, Virginia Semiconductor Inc., Fredericksburg, VA, 2003.

[3] R.K. Shah, A.L. London, Laminar Flow Forced Convection in Ducts: A Source Book for Compact Heat Exchanger Analytical Data, Academic Press, New York, 1978.

[4] S. Kakaç, R.K. Shah, W. Aung (Eds.), Handbook of Single-Phase Convective Heat Transfer, Wiley, New York, 1987, pp. 3.10-3.121.

[5] D.B. Tuckerman, R.F.W. Pease, High-performance heat sinking for VLSI, IEEE Electron Device Letters 2 (1981) 126-129.

[6] J. Judy, D. Maynes, B.W. Webb, Characterization of frictional pressure drop for liquid flows through microchannels, Int. J. Heat Mass Transfer 45 (2002) 3477-3489.

[7] D. Liu, S.V. Garimella, Investigation of liquid flow through microchannels, AIAA J. Thermophys. Heat Transfer 18 (2004) 65-72.

[8] P.S. Lee, D. Liu, S.V. Garimella, Investigation of heat transfer in rectangular microchannels, Int. J. Heat Mass Transfer 48 (2005) 1688-1704.

[9] R.K. Shah, Compact Heat Exchangers, in: W.M. Rohsenow, J.P. Hartnett, E.N. Ganić (Eds.), Handbook of Heat Transfer Applications McGraw-Hill, New York, 1985, pp. 4.217-4.218.

[10] R.J. Phillips, Microchannel Heat Sinks, in: A. Bar-Cohen, A.D. Kraus (Eds.), Advances in Thermal Modeling of Electronic Components and Systems 2, ASME Press, New York, 1990, pp. 109-184. 
[11] J. Harley, H. Bau, J.N. Zemel, V. Dominko, Fluid flow in micron and submicron size channels, Proc. IEEE Micro Electro Mechanical Systems: An Investigation of Micro Structures, Sensors, Actuators, Machines and Robots, 1989, pp. 25-28.

[12] S.M. Flockhart, R.S. Dhariwal, Experimental and numerical investigation into the flow characteristics of channels etched in <100> silicon, J. Fluids Eng. 120 (1998) 291-295.

[13] B. Farhanieh, B. Sunden, Three-dimensional laminar flow and heat transfer in the entrance region of trapezoidal ducts, Int. J. Num. Meth. Fluids 13 (1991) 537-556.

[14] J.R. Rujano, M.M. Rahman, Analysis and computation of conjugate heat transfer in trapezoidal microchannel heat sinks in a silicon substrate, ASME Heat Transfer Division, HTD 305, Heat Transfer in Microgravity Systems (1997) 175-185.

[15] W. Qu, G.M. Mala, D. Li, Heat transfer for water flow in trapezoidal silicon microchannels, Int. J. Heat Mass Transfer 43 (2000) 3925-3936.

[16] W. Qu, G.M. Mala, D. Li, Pressure-driven water flows in trapezoidal silicon microchannels, Int. J. Heat Mass Transfer 43 (2000) 353-364.

[17] M.M. Rahman, S.S. Shevade, Fluid flow and heat transfer in a composite trapezoidal microchannel, Proc. 2005 ASME Summer Heat Transfer Conference, 2005, pp. 411-417.

[18] H.Y. Wu, P. Cheng, Friction factors in smooth trapezoidal silicon microchannels with different aspect ratios, Int. J. Heat Mass Transfer 46 (2003) 2519-2525.

[19] H.Y. Wu, P. Cheng, An experimental study of convective heat transfer in silicon microchannels with different surface conditions, Int. J. Heat Mass Transfer 46 (2003) 2547-2556.

[20] S. Chen, T.L. Chan, C.W. Leung, B. Yu, Numerical prediction of laminar forced convection in triangular ducts with unstructured triangular grid method, Numerical Heat Transfer, Part A: Applications 38 (2000) 209-224.

[21] J.T. Dickey, T.T. Lam, Heat transfer in triangular microchannels, Advances in Electronic Packaging 2 (2003) 303-307.

[22] R. Sadasivam, R.M. Manglik, M.A. Jog, Fully developed forced convection through trapezoidal and hexagonal ducts, Int. J. Heat Mass Transfer 42 (1999) 4321-4331.

[23] M. Bahrami, M.M. Yovanovich, J.R. Culham, Pressure drop of fully-developed, laminar flow in microchannels of arbitrary cross-section, Proc. 3rd International Conf. on Microchannels and Minichannels, 2005, pp. 269-280. 
[24] M. Bahrami, M.M. Yovanovich, J.R. Culham, Pressure drop of fully-developed, laminar flow in rough microtubes, Proc. 3rd International Conf. on Microchannels and Minichannels, 2005, pp. 259-268.

[25] M. Bahrami, M.M. Yovanovich, J.R. Culham, Convective heat transfer of laminar, single-phase flow in randomly rough microtubes, Proc. 2005 ASME International Engineering Congress and Exposition, 2005, pp. 449-457.

[26] M.E. Steinke, S.G. Kandlikar, Single-phase liquid friction factors in microchannels, 3rd International Conference on Microchannels and Minichannels, Elsevier France-Editions Scientifiques Medicales Elsevier, 2005, pp. 1073-1083.

[27] M. Rokni, B. Sunden, Numerical investigation of turbulent forced convection in ducts with rectangular and trapezoidal cross-section area by using different turbulence models, Numerical Heat Transfer, Part A: Applications 30 (1996) 321 - 346.

[28] X. Wei, Y. Joshi, Stacked microchannel heat sinks for liquid cooling of microelectronic components, J. Electronic Packaging 126 (2004) 60-66.

[29] R.K. Shah, Thermal entry length solutions for the circular tube and parallel plates, Proc. 3rd National Heat and Mass Transfer Conf. 1, 1975, Pap. No. HMT-11-75.

[30] R.K. Shah, Laminar flow friction and forced convection heat transfer in ducts of arbitrary geometry, Int. J. Heat Mass Transf. 18 (1975) 849-862.

[31] P.S. Lee, S.V. Garimella, Thermally developing flow and heat transfer in rectangular microchannels of different aspect ratios, Int. J. Heat Mass Transfer 49 (2006) 3060-3067.

[32] P. Talukdar, M. Shah, Analysis of Laminar Mixed Convective Heat Transfer in Horizontal Triangular Ducts, Numerical Heat Transfer, Part A: Applications 54 (2008) 1148 - 1168 .

[33] M. Renksizbulut, H. Niazmand, Laminar flow and heat transfer in the entrance region of trapezoidal channels with constant wall temperature, J. Heat Transfer 128 (2006) 63-74.

[34] H. Niazmand, M. Renksizbulut, E. Saeedi, Developing slip-flow and heat transfer in trapezoidal microchannels, Int. J. Heat Mass Transf. 51 (2008) 6126-6135.

[35] G. Wang, L. Hao, P. Cheng, An experimental and numerical study of forced convection in a microchannel with negligible axial heat conduction, Int. J. Heat Mass Transf. 52 (2009) 1070-1074. 
[36] L. Graetz, On the thermal conductivity of liquids, Part 1, Ann. Phys. Chem. 18 (1883) 7994.

[37] L. Graetz, On the thermal conductivity of liquids, Part 2, Ann. Phys. Chem. 25 (1885) 337-357.

[38] W.M. Kays, Numerical solutions for laminar-flow heat transfer in circular tubes, Trans. ASME 77 (1955) 1265-1274.

[39] L.M. Lévêque, The laws of heat transmission by convection, Les Annales des Mines: Memoires 12-13 (1928) 201-299, 305-362, 381-415.

[40] W. Nusselt, Heat exchange in sprinkler coolers, VDI Z 67 (1923) 206-210.

[41] B.S. Petukhov, C. Chzhen-Yun, Heat transfer in the hydrodynamic inlet region of a round tube with laminar flow, Proc. 2nd All Soviet Union Conf. Heat and Mass Transfer 1 (1964) 193-204, English Trans. J. C. Gazley, J.P. Hartnett, E.R.G. Eckert (Eds.), Rand Corp., Santa Monica, CA, Rep. R-451-PR, 1966.

[42] R. Siegel, E.M. Sparrow, T.M. Hallman, Steady laminar heat transfer in a circular tube with prescribed wall heat flux, Appl. Sci. Res., Sect. A 7 (1958) 386-392.

[43] E.M. Sparrow, J.L. Novotny, S.H. Lin, Laminar flow of a heat-generating fluid in a parallel-plate channel, AIChE J. 9 (1963) 797-804.

[44] Fluent, Inc., FLUENT 6.2 user's guide, Fluent, Inc., Lebanon, NH, 2005.

[45] F.M. White, Viscous Fluid Flow, 2nd ed., McGraw-Hill, New York, 1991, ch. 3. 


\section{LIST OF TABLES}

Table 1. Comparison of studies in the literature applicable to thermally developing flow in trapezoidal microchannels.

Table 2. Test matrix for numerical simulations of microchannels with $\phi=54.7^{\circ}$ and $45^{\circ}$. Table 3. Values of $N u_{f d}$ and $f R e$ from present method compared with those of Shah [30] and analytical values.

Table 4. Correlations for friction constant, fully developed Nusselt number, thermal entrance length, local Nusselt number, and average Nusselt number in thermally developing flow with the $H I$ boundary condition. 


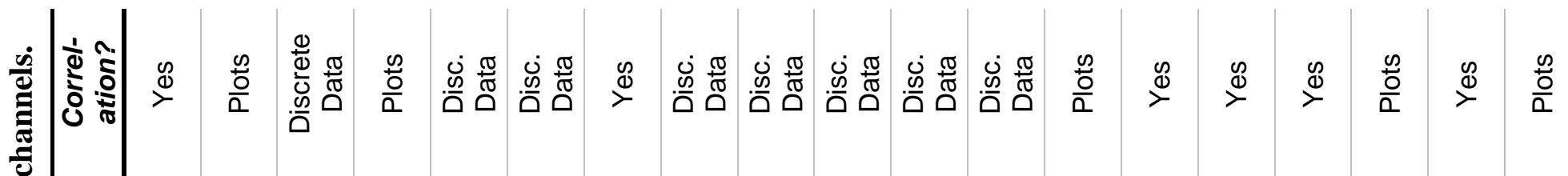

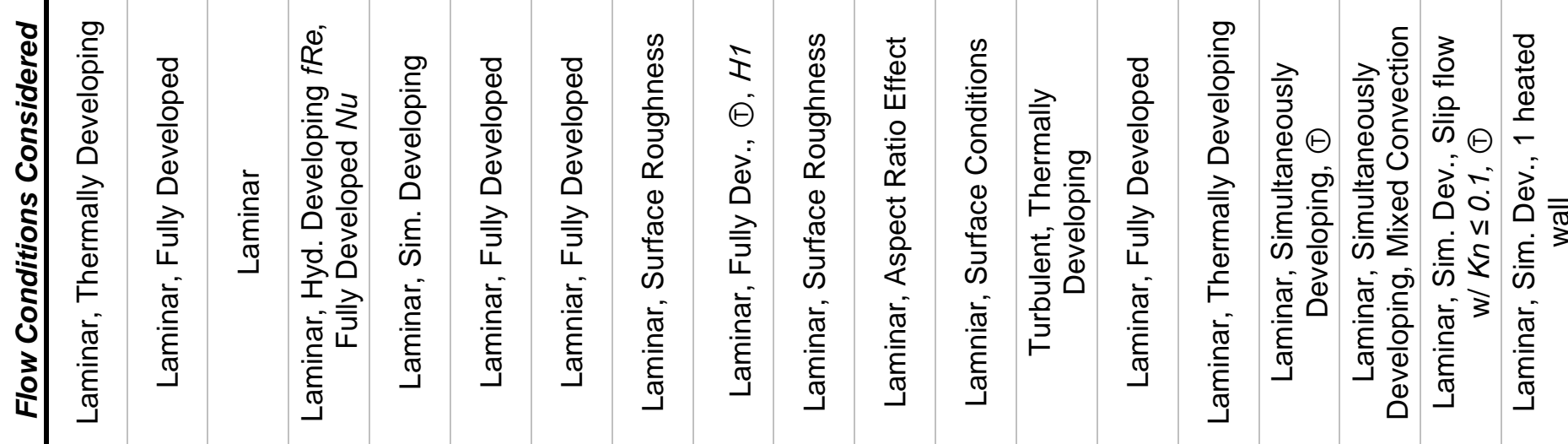

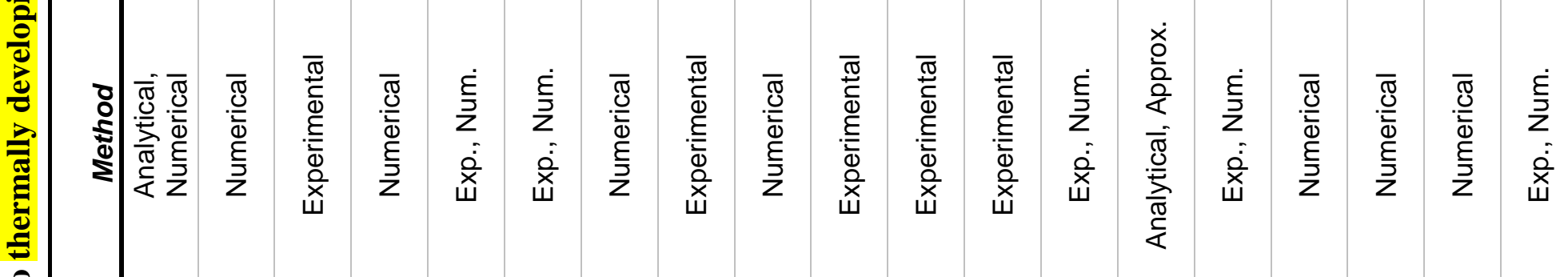

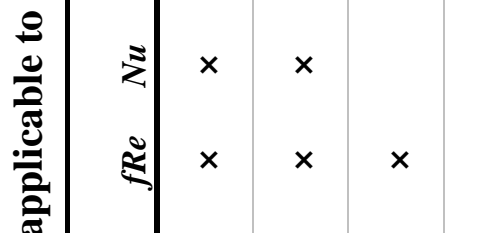

:

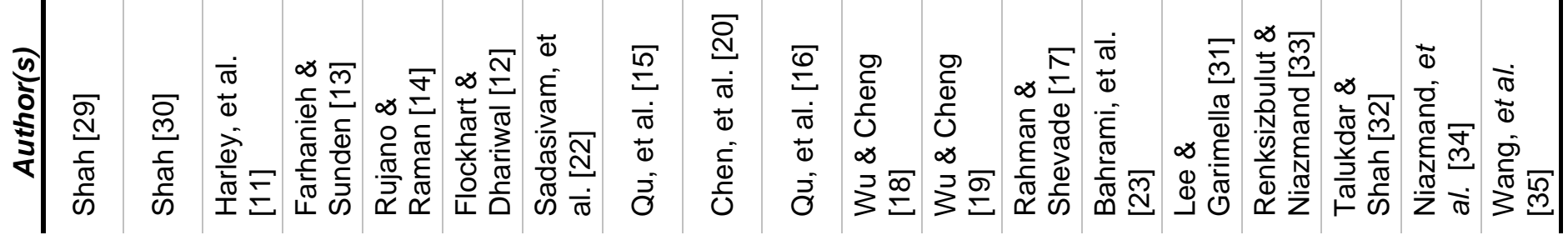


Table 2. Test matrix for numerical simulations of microchannels with $\phi=54.7^{\circ}$ and $45^{\circ}$.

\begin{tabular}{ccc}
\hline$\alpha$ & $\begin{array}{c}\mathbf{2 a} \\
/(\boldsymbol{\mu m})\end{array}$ & $\begin{array}{c}\mathbf{2 b} \\
/(\boldsymbol{\mu m})\end{array}$ \\
\hline 0 & 0 & 250 \\
0.05 & 12.5 & 250 \\
0.1 & 25 & 250 \\
0.5 & 125 & 250 \\
0.75 & 93.75 & 250 \\
1 & 250 & 250 \\
1.5 & 375 & 250 \\
2 & 500 & 250 \\
3 & 750 & 250 \\
4 & 1,000 & 250 \\
5 & 1,250 & 250 \\
6 & 1,500 & 250 \\
7 & 1,750 & 250 \\
8 & 2,000 & 250 \\
10 & 2,500 & 250 \\
20 & 5,000 & 250 \\
50 & 12,500 & 250 \\
100 & 25,000 & 250 \\
\hline & &
\end{tabular}


Table 3. Values of $N u_{f d}$ and $f R e$ from present method compared with those of Shah [30] and analytical values.

\begin{tabular}{|c|c|c|c|c|c|c|c|c|}
\hline \multicolumn{9}{|c|}{$f R e$} \\
\hline \multirow[b]{2}{*}{$\alpha$} & \multirow{2}{*}{$\begin{array}{c}\text { Shah, } 45^{\circ} \\
{[30]}\end{array}$} & \multicolumn{4}{|c|}{ present, $45^{\circ}$} & \multicolumn{3}{|c|}{ present, $54.7^{\circ}$} \\
\hline & & Analyt. & $\varepsilon_{A . / S}$ & Numer. & $\varepsilon_{N / A}$ & Analyt. & Numer. & $\varepsilon_{F / A}$ \\
\hline 0.05 & & 13.241 & & 13.223 & $-0.13 \%$ & 13.509 & 13.492 & $-0.12 \%$ \\
\hline 0.1 & & 13.290 & & 13.293 & $0.03 \%$ & 13.623 & 13.592 & $-0.23 \%$ \\
\hline 0.25 & 13.323 & 13.324 & $0.01 \%$ & 13.333 & $0.06 \%$ & 13.691 & & \\
\hline 0.5 & 13.364 & 13.369 & $0.03 \%$ & 13.374 & $0.04 \%$ & 13.654 & 13.639 & $-0.11 \%$ \\
\hline 0.75 & 13.541 & 13.544 & $0.02 \%$ & 13.557 & $0.10 \%$ & 13.785 & 13.772 & $-0.09 \%$ \\
\hline 1 & 13.827 & 13.822 & $-0.04 \%$ & 13.831 & $0.07 \%$ & 14.064 & 14.180 & $0.83 \%$ \\
\hline 1.5 & & 14.508 & & 14.511 & $0.02 \%$ & 14.802 & 14.780 & $-0.15 \%$ \\
\hline 2 & 15.206 & 15.212 & $0.04 \%$ & 15.201 & $-0.07 \%$ & 15.566 & 15.541 & $-0.16 \%$ \\
\hline 3 & & 16.447 & & 16.425 & $-0.13 \%$ & 16.879 & 17.293 & $2.45 \%$ \\
\hline 4 & 17.397 & 17.420 & $0.13 \%$ & 17.389 & $-0.18 \%$ & 17.881 & 17.545 & $-1.88 \%$ \\
\hline 5 & & 18.184 & & 18.149 & $-0.20 \%$ & 18.650 & 18.680 & $0.16 \%$ \\
\hline 6 & & 18.796 & & 18.755 & $-0.22 \%$ & 19.252 & 19.207 & $-0.23 \%$ \\
\hline 7 & & 19.294 & & 19.250 & $-0.23 \%$ & 19.736 & 19.678 & $-0.29 \%$ \\
\hline 8 & 19.743 & 19.706 & $-0.19 \%$ & 19.659 & $-0.24 \%$ & 20.131 & 20.068 & $-0.31 \%$ \\
\hline 10 & & 20.349 & & 20.296 & $-0.26 \%$ & 20.737 & 20.658 & $-0.38 \%$ \\
\hline 20 & & 21.915 & & 21.837 & $-0.36 \%$ & 22.174 & 21.520 & $-2.95 \%$ \\
\hline 50 & & 23.087 & & 22.968 & $-0.51 \%$ & 23.212 & 22.360 & $-3.67 \%$ \\
\hline 100 & & 23.521 & & 23.405 & $-0.49 \%$ & 23.590 & 23.471 & $-0.50 \%$ \\
\hline \multicolumn{9}{|c|}{$N u_{f d}$} \\
\hline \multirow[b]{2}{*}{$\alpha$} & \multirow{2}{*}{$\begin{array}{c}\text { Shah, } 45^{\circ} \\
{[30]}\end{array}$} & \multicolumn{4}{|c|}{ present, $45^{\circ}$} & \multicolumn{3}{|c|}{ present, $54.7^{\circ}$} \\
\hline & & Analyt. & $\varepsilon_{A . / S}$ & Numer. & $\varepsilon_{N / A}$ & Analyt. & Numer. & $\varepsilon_{F / A}$ \\
\hline 0.05 & & 3.005 & & 3.033 & $0.93 \%$ & 3.146 & 3.170 & $0.76 \%$ \\
\hline 0.1 & & 3.023 & & 3.054 & $1.03 \%$ & 3.188 & 3.221 & $1.03 \%$ \\
\hline 0.25 & 3.048 & 3.049 & $0.03 \%$ & 3.079 & $0.99 \%$ & 3.246 & & \\
\hline 0.5 & 3.081 & 3.080 & $-0.04 \%$ & 3.107 & $0.89 \%$ & 3.261 & 3.285 & $0.74 \%$ \\
\hline 0.75 & 3.155 & 3.155 & $0.01 \%$ & 3.188 & $1.03 \%$ & 3.319 & 3.341 & $0.67 \%$ \\
\hline 1 & 3.268 & 3.272 & $0.13 \%$ & 3.304 & $0.96 \%$ & 3.431 & 3.465 & $0.97 \%$ \\
\hline 1.5 & & 3.569 & & 3.602 & $0.91 \%$ & 3.739 & 3.748 & $0.24 \%$ \\
\hline 2 & 3.888 & 3.886 & $-0.06 \%$ & 3.907 & $0.56 \%$ & 4.073 & 4.104 & $0.76 \%$ \\
\hline 3 & & 4.464 & & 4.484 & $0.45 \%$ & 4.678 & 4.697 & $0.40 \%$ \\
\hline 4 & 4.943 & 4.933 & $-0.20 \%$ & 4.949 & $0.32 \%$ & 5.160 & 5.198 & $0.75 \%$ \\
\hline 5 & & 5.307 & & 5.323 & $0.30 \%$ & 5.536 & 5.555 & $0.36 \%$ \\
\hline 6 & & 5.609 & & 5.624 & $0.27 \%$ & 5.833 & 5.849 & $0.27 \%$ \\
\hline 7 & & 5.856 & & 5.874 & $0.30 \%$ & 6.073 & 6.092 & $0.31 \%$ \\
\hline 8 & 6.034 & 6.062 & $0.46 \%$ & 6.081 & $0.31 \%$ & 6.271 & 6.289 & $0.29 \%$ \\
\hline 10 & & 6.383 & & 6.406 & $0.36 \%$ & 6.575 & 6.599 & $0.36 \%$ \\
\hline 20 & & 7.173 & & 7.211 & $0.53 \%$ & 7.302 & 7.351 & $0.67 \%$ \\
\hline 50 & & 7.769 & & 7.821 & $0.68 \%$ & 7.830 & 7.867 & $0.47 \%$ \\
\hline 100 & & 8.015 & & 8.029 & $0.18 \%$ & 8.027 & 8.056 & $0.36 \%$ \\
\hline
\end{tabular}


Table 4. Correlations for friction constant, fully developed Nusselt number, thermal entrance length, local Nusselt number, and average Nusselt number in thermally developing flow with the $H 1$ boundary condition.

\begin{tabular}{|c|c|c|c|c|c|}
\hline$\phi_{s}$ & Qty & Correlation Equation & Limits & $\begin{array}{l}E q \\
\text { No. }\end{array}$ & $\begin{array}{c}M A E^{a} \\
(\%)\end{array}$ \\
\hline \multirow{3}{*}{$54.7^{\circ}$} & fRe & $=13.35+10.74 \exp \{-\exp [-0.85(\ln (\alpha)-1.25)]\}$ & $0 \leq \alpha \leq 1100$ & (9) & 1.20 \\
\hline & $N u_{f d}$ & $=\left\{\begin{array}{l}3.121 \\
3.265+5.075 \exp \{-\exp [-0.9041(\ln (\alpha)-1.3496)]\} \\
8.235\end{array}\right.$ & $\begin{array}{r}0 \leq \alpha<0.1 \\
0.1 \leq \alpha<250 \\
250 \leq \alpha<\infty\end{array}$ & $(10)$ & 0.40 \\
\hline & $L_{t h}^{*}$ & $=\left\{\begin{array}{l}0.07227 \\
0.04221-0.02192 \tan ^{-1}[1.3578(\ln (\alpha)-0.9560)] \\
0.01154\end{array}\right.$ & $\begin{array}{r}0 \leq \alpha<0.1 \\
0.1 \leq \alpha<200 \\
200 \leq \alpha<\infty\end{array}$ & $(11)$ & 1.30 \\
\hline \multirow{3}{*}{$45^{\circ}$} & fRe & $=13.35+10.74 \exp \{-\exp [-0.86(\ln (\alpha)-1.35)]\}$ & $0 \leq \alpha \leq 1100$ & $(12)$ & 0.25 \\
\hline & $N u_{f d}$ & $=\left\{\begin{array}{l}3.032 \\
3.093+5.322 \exp \{-\exp [-0.8494(\ln (\alpha)-1.4353)]\} \\
8.235\end{array}\right.$ & $\begin{array}{r}0 \leq \alpha<0.1 \\
0.1 \leq \alpha<220 \\
220 \leq \alpha<\infty\end{array}$ & $(13)$ & 0.40 \\
\hline & $L_{t h}^{*}$ & $=\left\{\begin{array}{l}0.07778 \\
0.07637-0.06503 \exp \{-\exp [-1.1974(\ln (\alpha)-0.6610)]\} \\
0.01154\end{array}\right.$ & $\begin{array}{r}0 \leq \alpha<0.1 \\
0.1 \leq \alpha<220 \\
220 \leq \alpha<\infty\end{array}$ & $(14)$ & 1.40 \\
\hline$\phi_{s}$ & Qty & Correlation Equation & Limits & $\begin{array}{c}E q \\
\text { No. }\end{array}$ & $\begin{array}{c}\text { Typ. } \\
\text { Error }^{b} \\
(\%)\end{array}$ \\
\hline \multirow[t]{2}{*}{$\begin{array}{c}54.7^{\circ} \\
\text { and } \\
45^{\circ}\end{array}$} & $\frac{N u_{z}}{N u_{f d}}$ & $\frac{\zeta \equiv \frac{z^{*}}{L_{t h}^{*}}, N u_{z}\left(L_{t h}^{*}\right)=1.05 \cdot N u_{f d}}{=\left\{\begin{array}{l}0.786 \cdot \zeta^{-1 / 3} \\
0.843 \cdot \zeta^{-0.318} \\
1+0.298 \cdot \zeta^{-0.506} \cdot e^{-1.992 \zeta}\end{array}\right.}$ & $\begin{array}{r}0<\zeta<0.008 \\
0.008 \leq \zeta<0.08 \\
0.08 \leq \zeta<\infty\end{array}$ & (15) & 2.0 \\
\hline & $\frac{N u_{\text {avg }}}{N u_{f d}}$ & $=\left\{\begin{array}{l}1.048 \cdot(\zeta)^{-1 / 3} \\
1.203 \cdot(\zeta)^{-0.29} \\
1+0.2189 / \zeta\end{array}\right.$ & $\begin{array}{r}0<\zeta<0.04 \\
0.04 \leq \zeta<0.8 \\
0.8 \leq \zeta<\infty\end{array}$ & $(16)$ & 3.1 \\
\hline
\end{tabular}

a"MAE" refers to "mean absolute error" of the correlation with respect to the numerical data.

b، Typ. Error” refers to typical error, a weighted average absolute percent value of the discrepancy between the correlation and the numerical data, with less weight being given to very small values of $\zeta$. 


\section{LIST OF FIGURES}

Figure 1. Exact solution for local, average, and mean Nusselt numbers in the parallel-plates thermal entrance problem. The tabulated data of Shah [29] for local and mean Nusselt numbers are shown as superposed symbols.

Figure 2. (a) Generalized trapezoidal duct cross-sectional parameters. The computational domain is shown with a bold dashed line. The sidewall angles $\phi$ in the present work are $54.7^{\circ}$ and $45^{\circ}$. (b) Numerical mesh at the entrance of the duct showing the half-channel computational domain. Central cells are large and cells near the wall are small in $x$ and $y$, while every cell is small in $z$ near the entrance. The mesh becomes uniform by the end of the thermal development region. The $15 \times 20 \times 365$ mesh is shown for clarity, although a finer mesh $(30 \times$ $40 \times 365)$ is used in the computations.

Figure 3. (a) Local Nusselt number as a function of dimensionless axial distance for the $15 \times 20$ $\times 365,30 \times 40 \times 365$, and $40 \times 60 \times 365$ grids used to establish grid independence at $\alpha=2$. (b) Local Nusselt number as a function of dimensionless axial distance for the different discretization methods used to establish order independence at $\alpha=2$.

Figure 4. Variation of fully developed friction factor with channel aspect ratio for trapezoidal channels of various aspect ratios. Included are the numerical results from the present work, the correlation equations (9) and (12) from the present work, the experimental data of $\mathrm{Wu}$ and Cheng [18], and the correlations from [18] and Sadasivam, et al. [22] for $\phi=54.7^{\circ}$ and $45^{\circ}$, respectively.

Figure 5. Numerical results of (a) local and (b) average Nusselt number as a function of axial location for $\phi=54.7^{\circ}$. Dimensionless thermal development lengths ( $\left.L_{t h}^{*}\right)$ are shown for the two limiting cases in Figure (a).

Figure 6. Variation of thermal development length (left axis) and fully developed Nusselt number (right axis) with channel aspect ratio for trapezoidal channels with sidewall angle of (a) $54.7^{\circ}$, and (b) $45^{\circ}$.

Figure 7. Representative predictions from Equations (15) and (16) for $N u_{z}$ and $N u_{a v g}$, respectively, at selected aspect ratios for $\phi=54.7^{\circ}$, compared to numerical results.

Figure 8. Effect of Prandtl number on the numerically calculated local Nusselt number for $\alpha=2$ and $\phi=54.7^{\circ}$. The correlation for local Nusselt number in thermally developing flow described by Equation (15), also shown in the figure, becomes less valid as Prandtl number decreases towards zero, leading to the existence of simultaneously developing flow. 


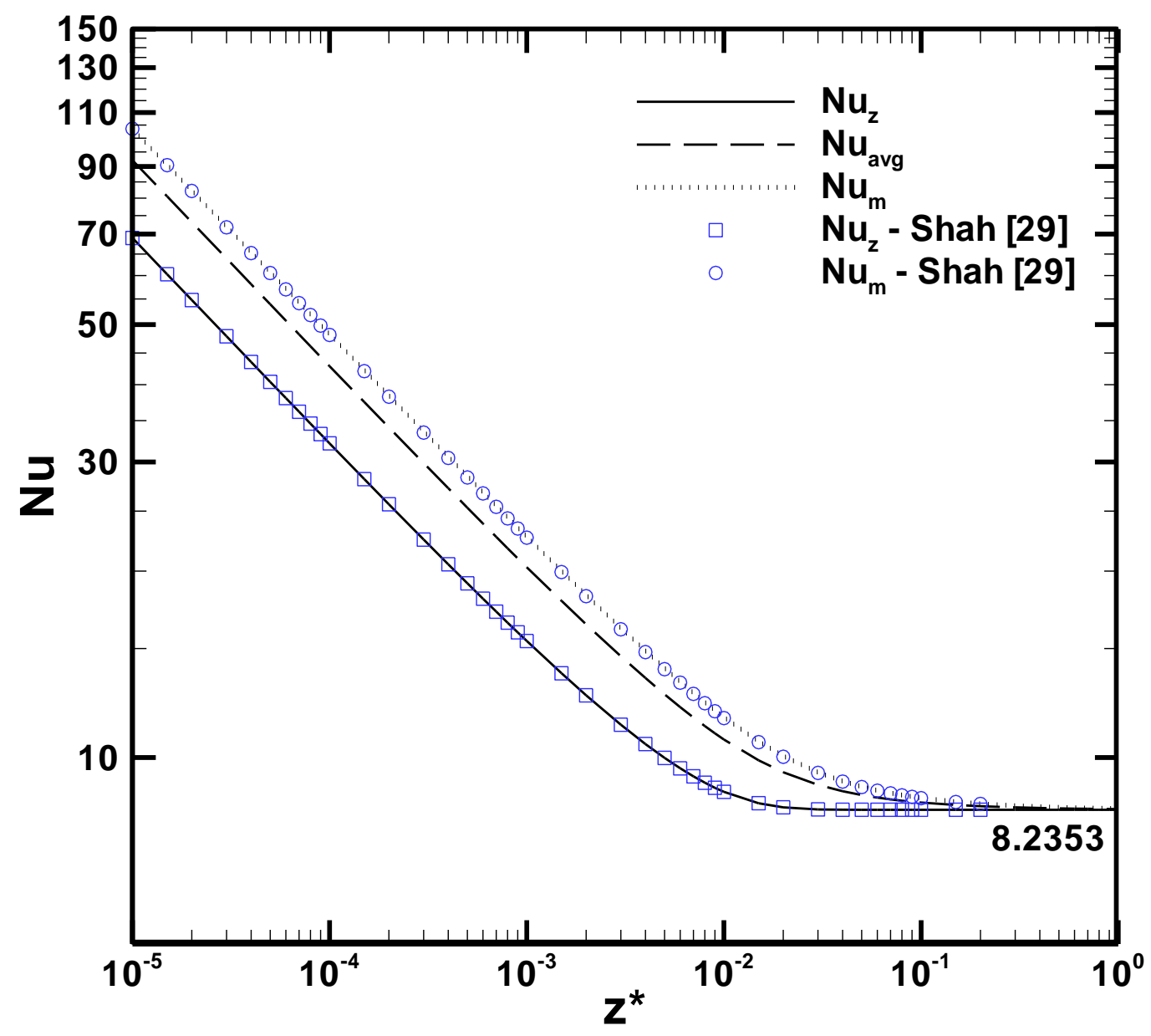

Figure 1. Exact solution for local, average, and mean Nusselt numbers in the parallelplates thermal entrance problem. The tabulated data of Shah [29] for local and mean Nusselt numbers are shown as superposed symbols. 


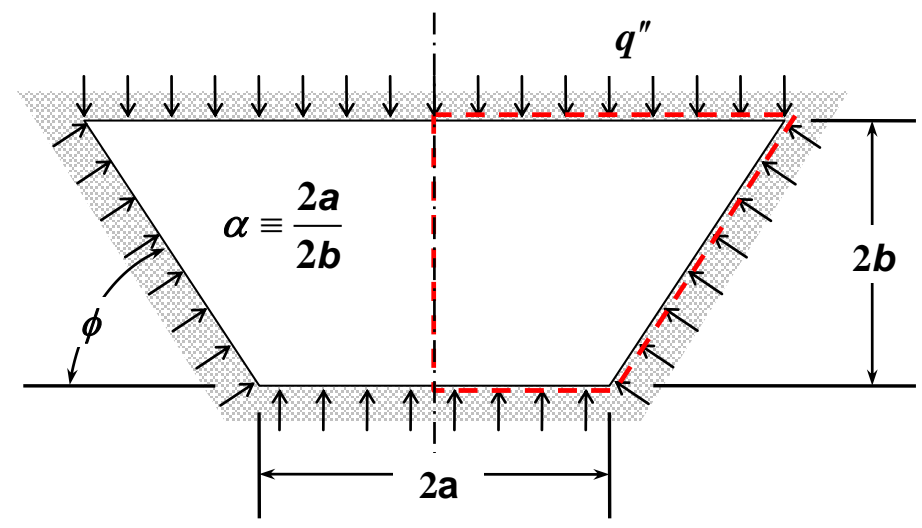

(a)

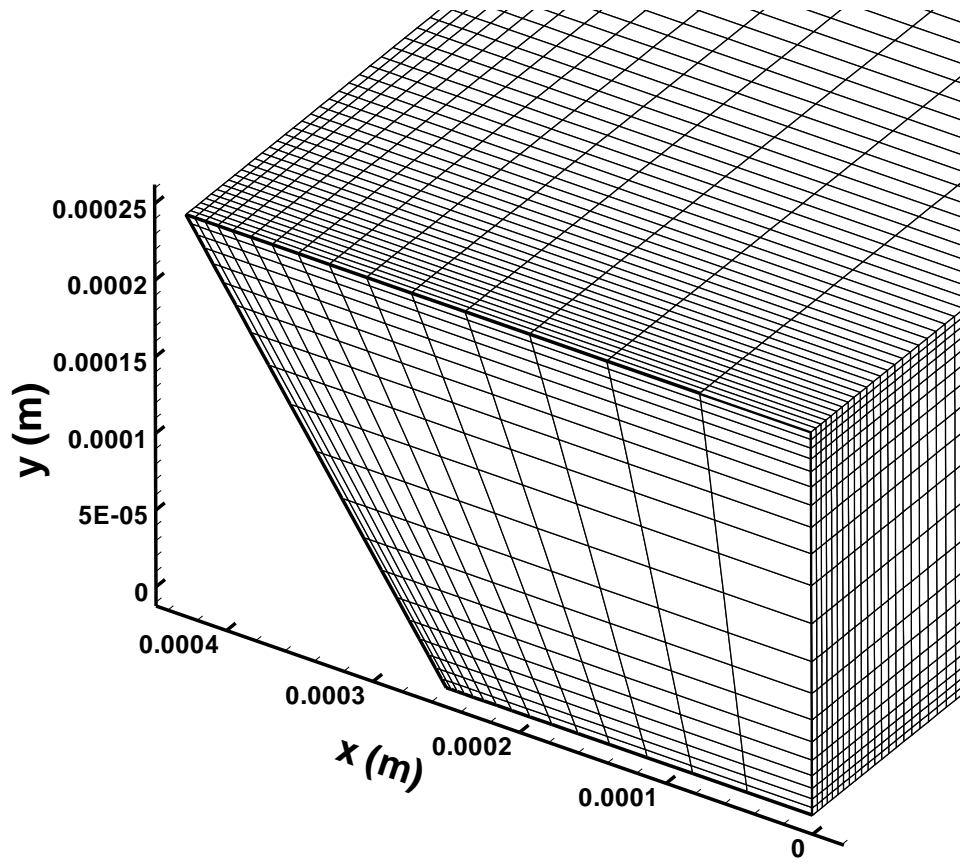

(b)

Figure 2. (a) Generalized trapezoidal duct cross-sectional parameters. The computational domain is shown with a bold dashed line. The sidewall angles $\phi$ in the present work are $54.7^{\circ}$ and $45^{\circ}$. (b) Numerical mesh at the entrance of the duct showing the half-channel computational domain. Central cells are large and cells near the wall are small in $x$ and $y$, while every cell is small in $z$ near the entrance. The mesh becomes uniform by the end of the thermal development region. The $15 \times 20 \times 365$ mesh is shown for clarity, although a finer mesh $(30 \times 40 \times 365)$ is used in the computations. 


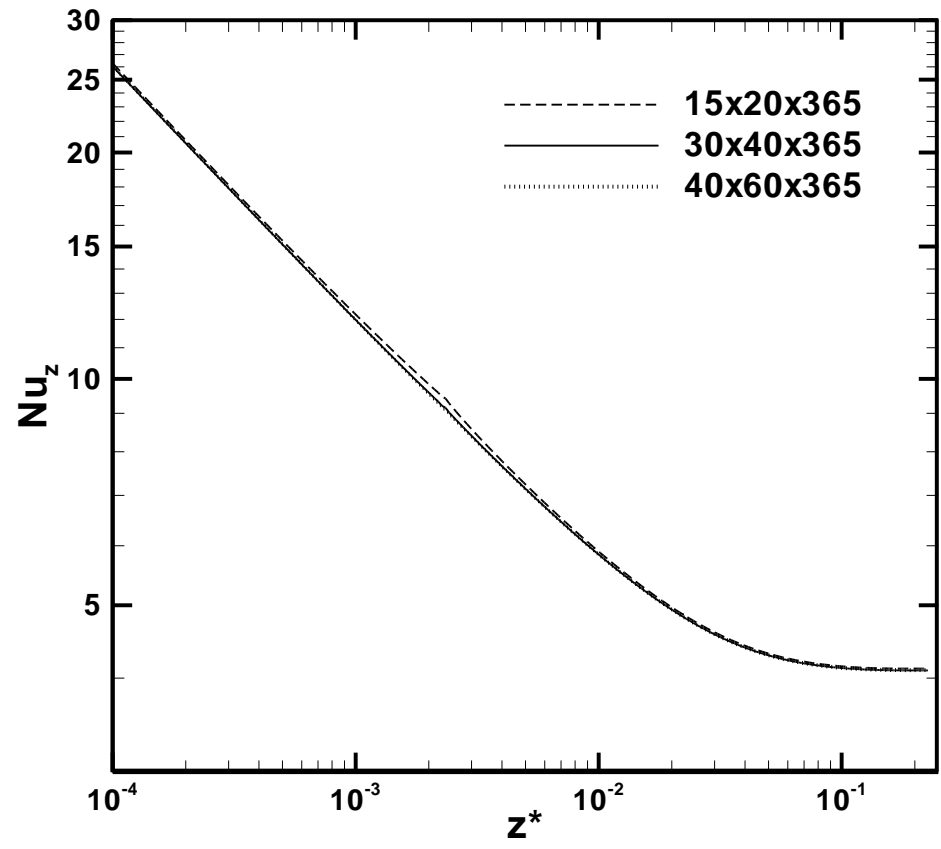

(a)

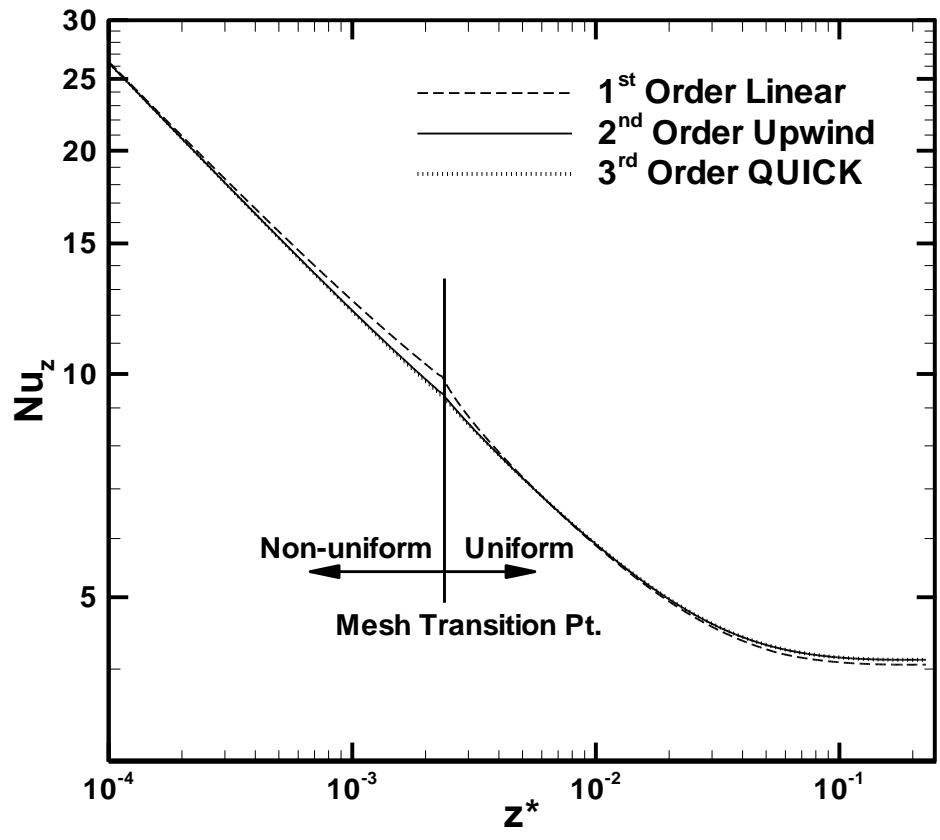

(b)

Figure 3. (a) Local Nusselt number as a function of dimensionless axial distance for the $15 \times 20 \times 365,30 \times 40 \times 365$, and $40 \times 60 \times 365$ grids used to establish grid independence at $\alpha=2$. (b) Local Nusselt number as a function of dimensionless axial distance for the different discretization methods used to establish order independence at $\alpha=2$. 


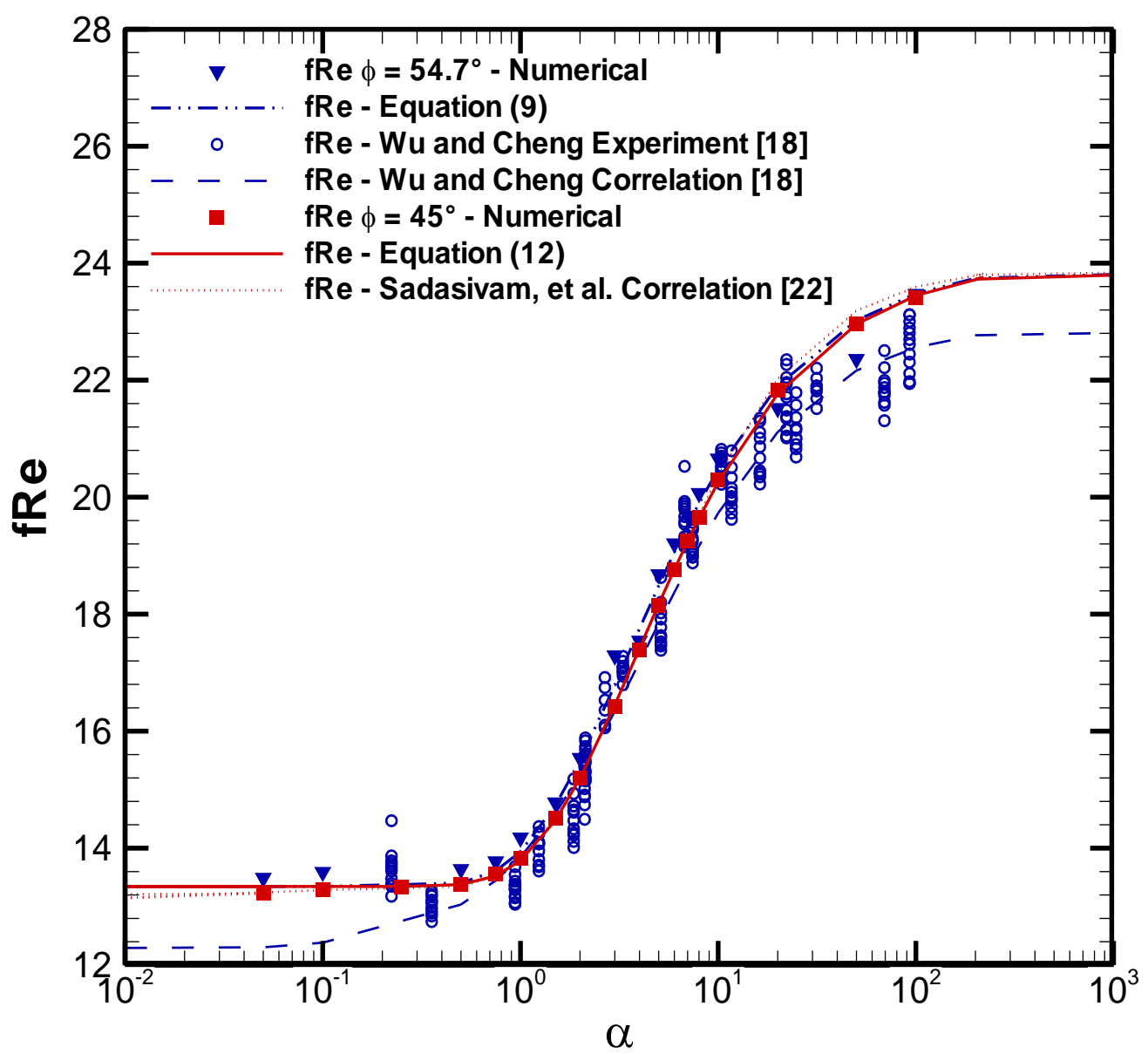

Figure 4. Variation of fully developed friction factor with channel aspect ratio for trapezoidal channels of various aspect ratios. Included are the numerical results from the present work, the correlation equations (9) and (12) from the present work, the experimental data of $\mathrm{Wu}$ and Cheng [18], and the correlations from [18] and Sadasivam, et al. [22] for $\phi=54.7^{\circ}$ and $45^{\circ}$, respectively. 


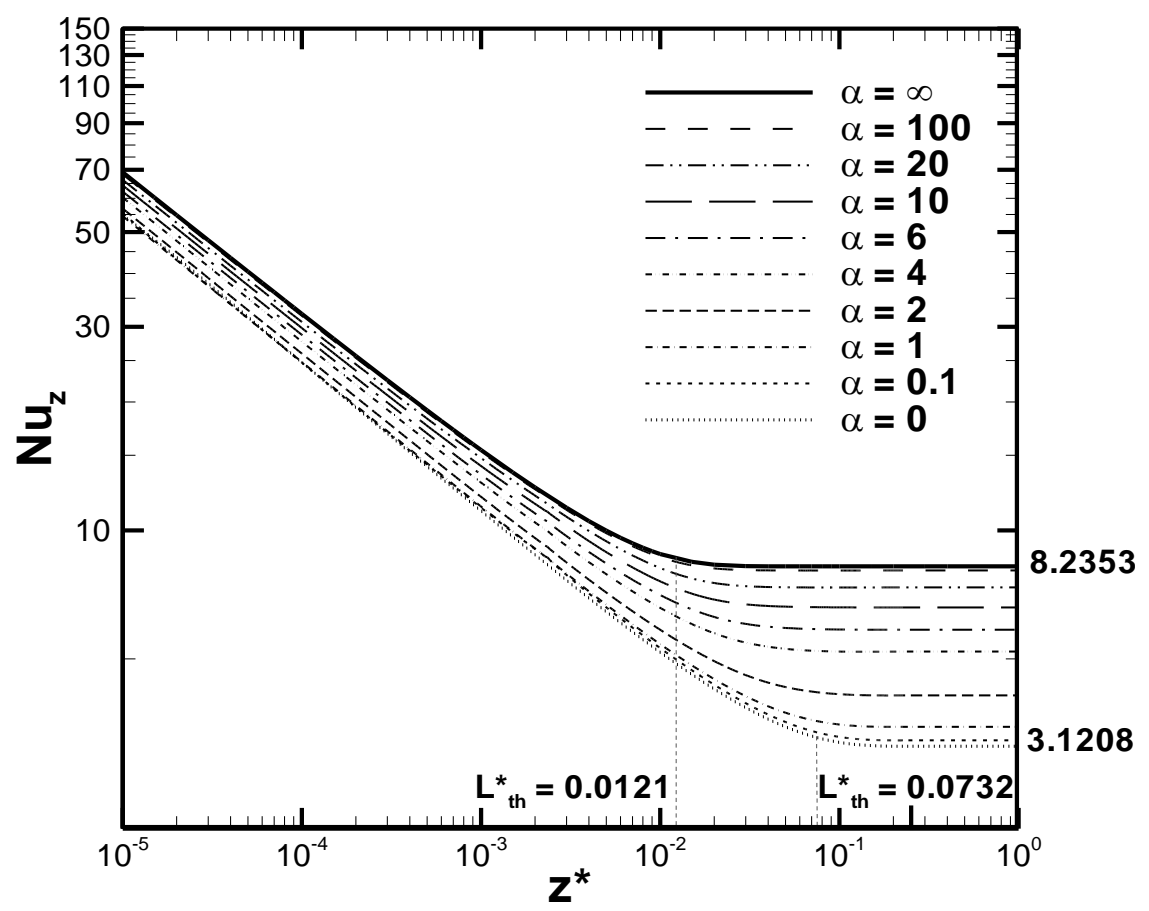

(a)

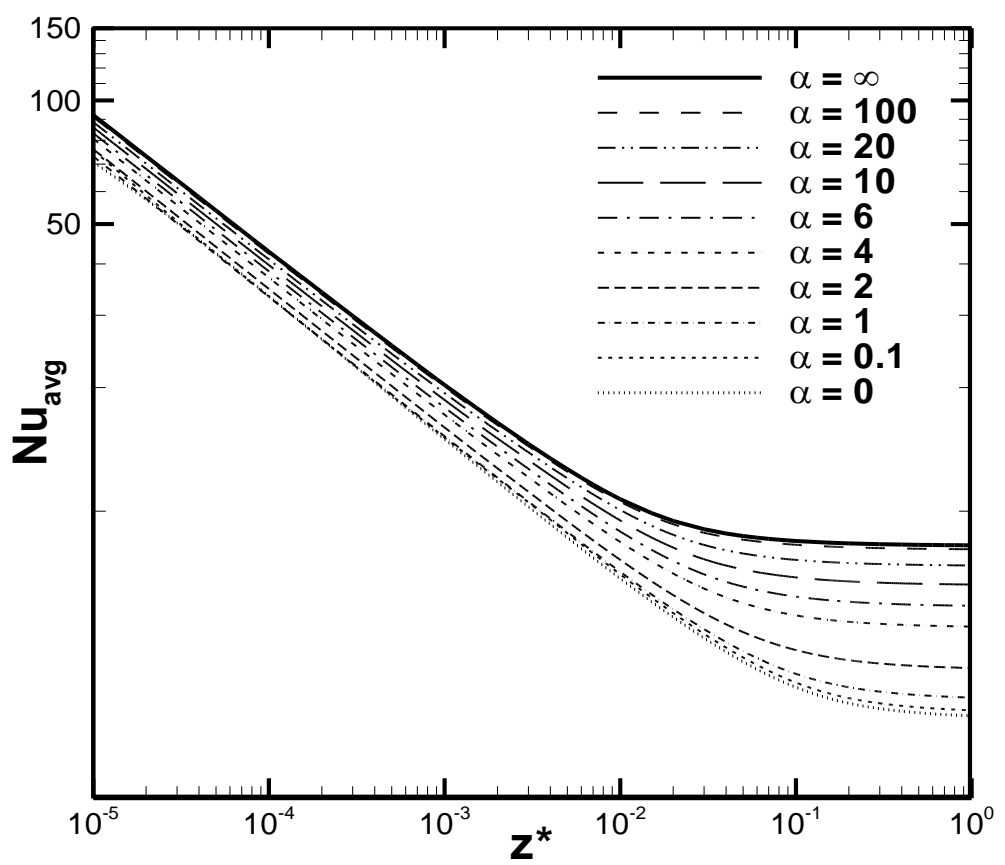

(b)

Figure 5. Numerical results of (a) local and (b) average Nusselt number as a function of axial location for $\phi=54.7^{\circ}$. Dimensionless thermal development lengths $\left(L_{t h}^{*}\right)$ are shown for the two limiting cases in Figure (a). 


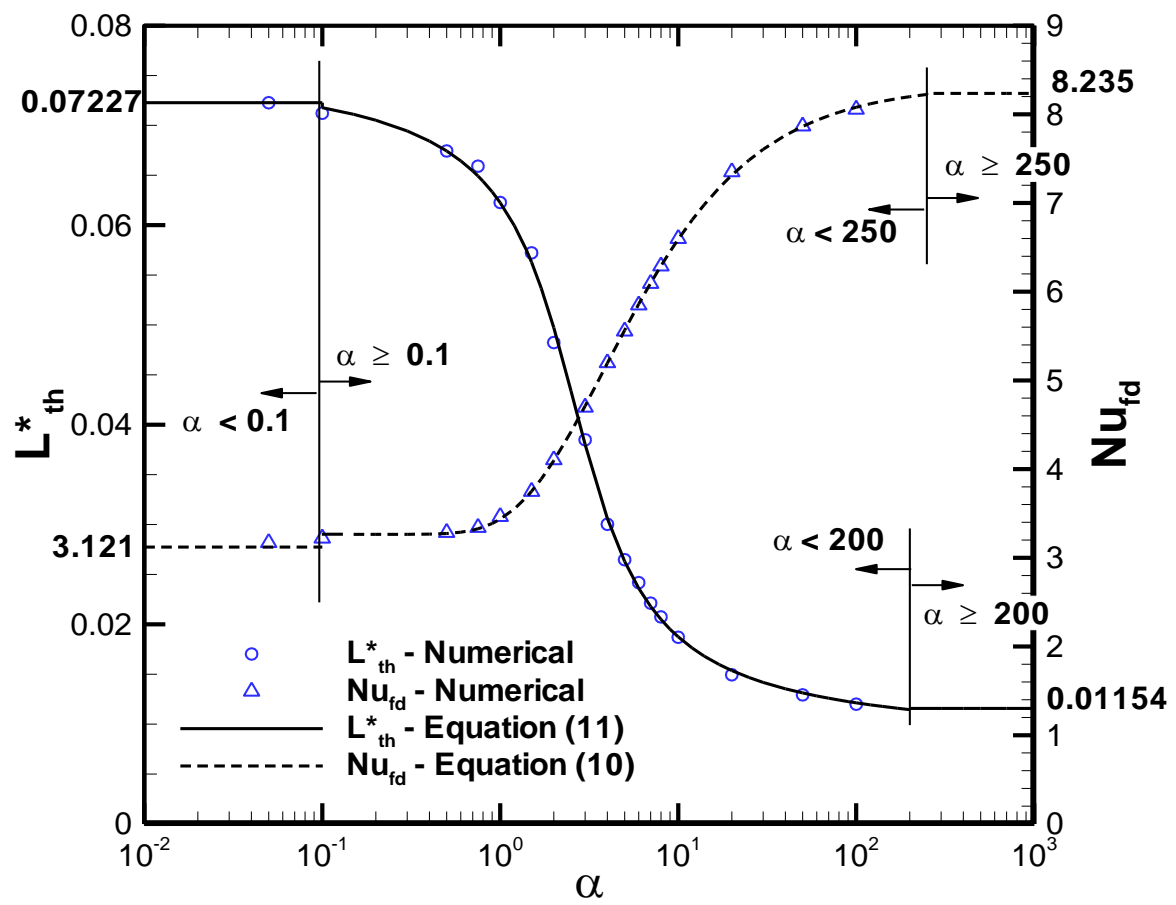

(a)

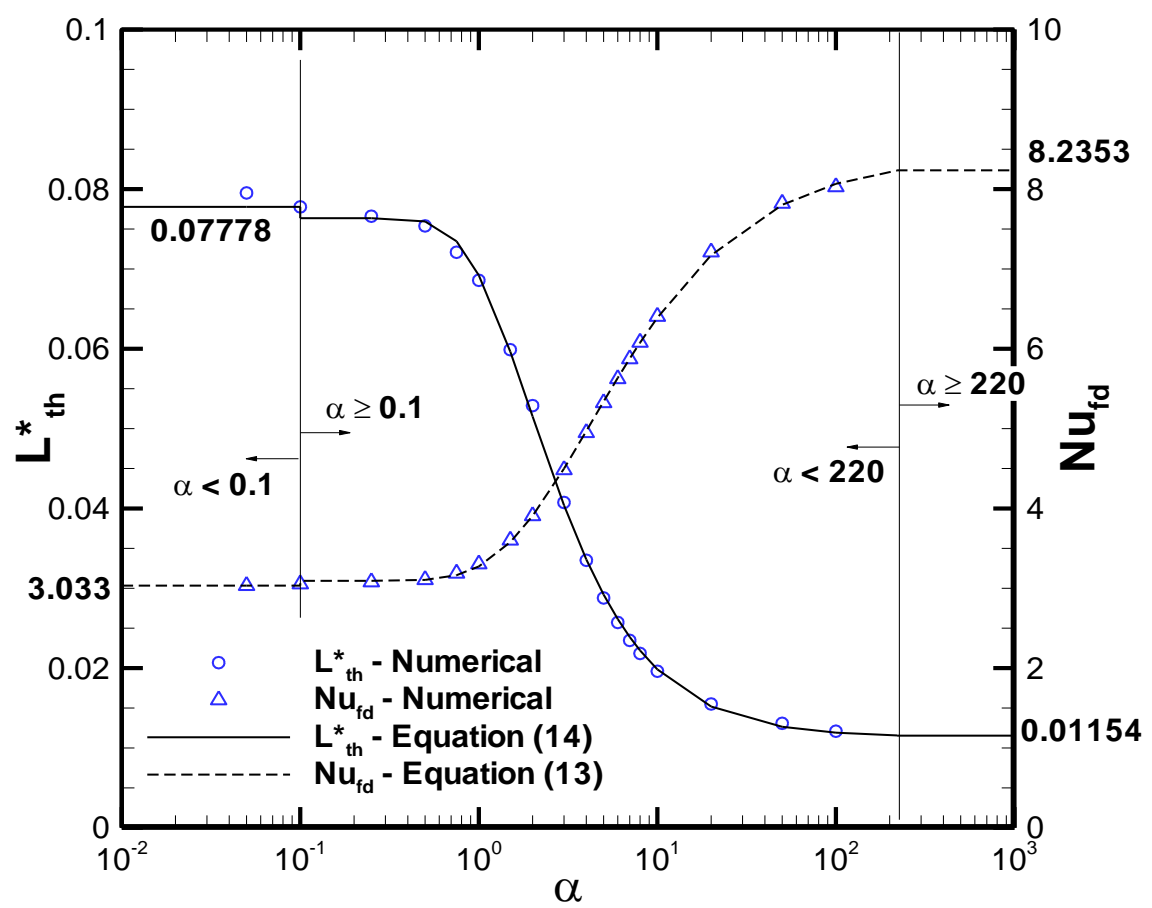

(b)

Figure 6. Variation of thermal development length (left axis) and fully developed Nusselt number (right axis) with channel aspect ratio for trapezoidal channels with sidewall angle of (a) $54.7^{\circ}$, and (b) $45^{\circ}$. 


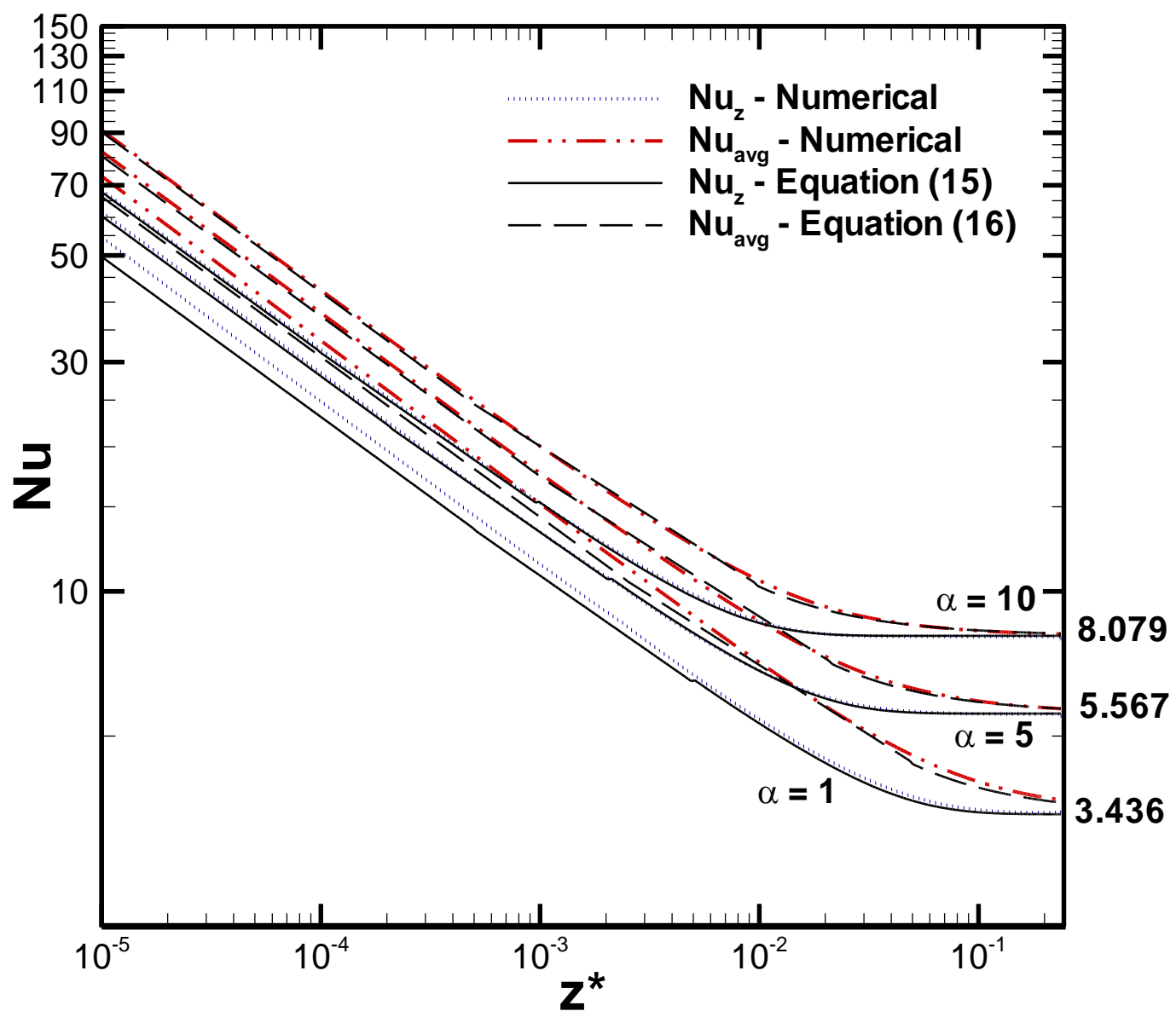

Figure 7. Representative predictions from Equations (15) and (16) for $N u_{z}$ and $N u_{a v g}$, respectively, at selected aspect ratios for $\phi=54.7^{\circ}$, compared to numerical results. 


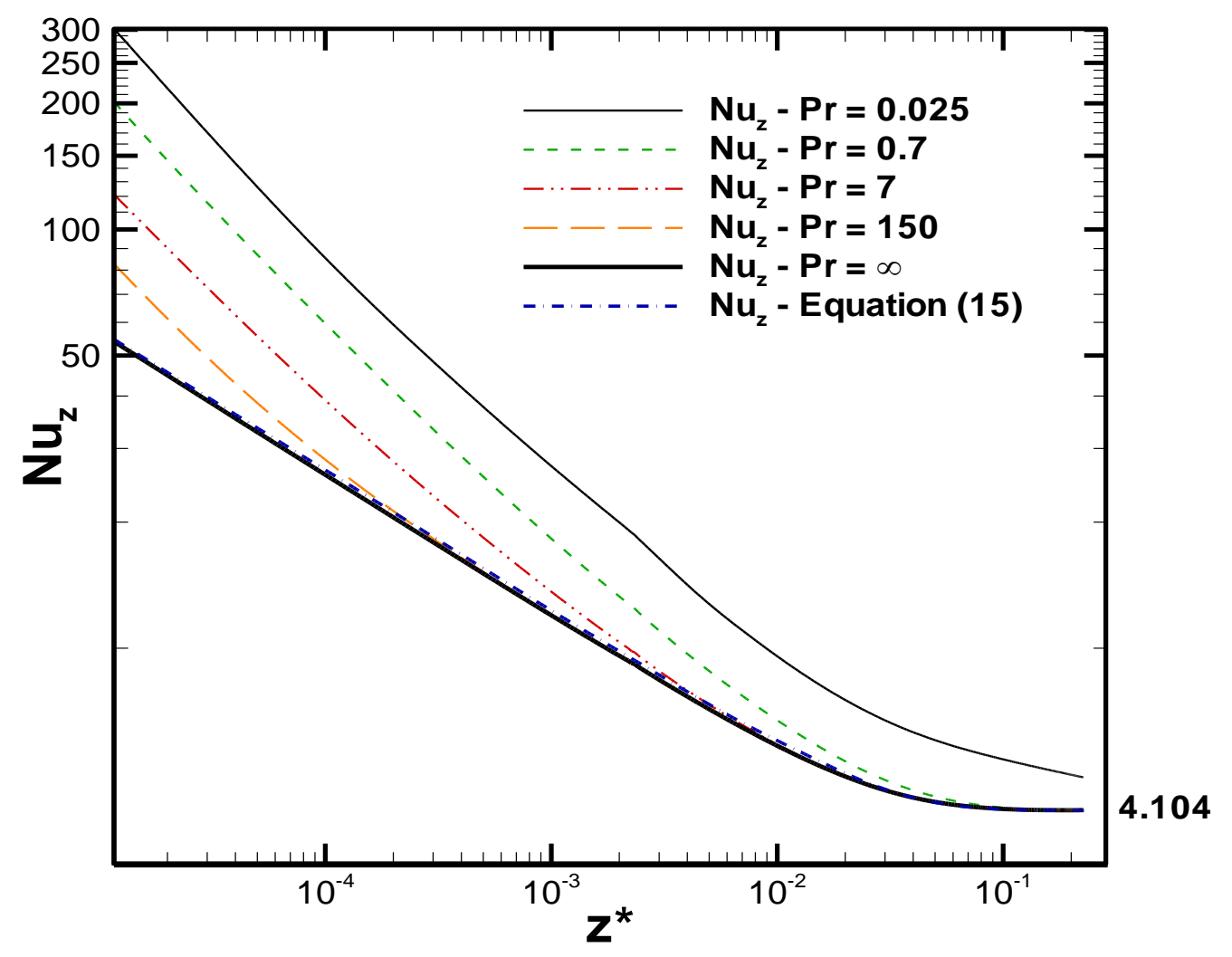

Figure 8. Effect of Prandtl number on the numerically calculated local Nusselt number for $\alpha=2$ and $\phi=54.7^{\circ}$. The correlation for local Nusselt number in thermally developing flow described by Equation (15), also shown in the figure, becomes less valid as Prandtl number decreases towards zero, leading to the existence of simultaneously developing flow. 